\title{
Nicotine microaerosol inhaler
}

\author{
Paul G Andrus MD ${ }^{1}$, Rod Rhem BSc ${ }^{1,2}$, Jack Rosenfeld PhD ${ }^{3}$, Myrna B Dolovich PEng ${ }^{1,2}$ \\ ${ }^{1}$ Aerosol Research Laboratory and ${ }^{2}$ Departments of Medicine, and ${ }^{3}$ Pathology, \\ McMaster University, Hamilton, Ontario
}

\section{PG Andrus, R Rhem, J Rosenfeld, MB Dolovich. Nicotine microaerosol inhaler. Can Respir J 1999;6(6):509-512.}

OBJECTIVE: To measure the droplet size distribution of a nicotine pressurized metered-dose inhaler using a nicotine in ethanol solution formulation with hydrofluoroalkane as propellant.

MATERIALS AND METHODS: Sizing was performed at room temperature by multistage liquid impinger and quartz crystal impactor.

RESULTS: The mass median aerodynamic diameter of the nicotine aerosol produced was measured at $1.6 \mu \mathrm{m}$ by multistage liquid impinger and $1.5 \mu \mathrm{m}$ by quartz crystal impactor. CONCLUSIONS: The inhaler formulation used produces a microaerosol of sufficiently fine droplet size that mimics the puff-by-puff pulmonary arterial bolus nicotine delivery of tobacco smoke. The absence of combustion products such as heat, carcinogens and carbon monoxide permits safer nicotine delivery via the inhaler than is possible via smoked tobacco.

Key Words: Hydrofluoroalkane propellant; Microaerosol; Nicotine; Pressurized metered-dose inhaler; Vapour

\section{Inhalateur de nicotine en microaérosol}

OBJECTIF : Mesurer la distribution de la taille des gouttelettes d'un aérosol-doseur sous pression contenant de la nicotine dans une solution d'éthanol et utilisant l'hydrofluoroalkane comme propulseur.

MATÉRIEL ET MÉTHODES : La détermination de la taille a été réalisée à la température ambiante par un impacteur en cascade et un impacteur piézoélectrique.

RÉSULTATS : Le diamètre aérodynamique médian de la masse de l'aérosol de nicotine produit a été mesuré à 1,6 mm par l'impacteur en cascade et à $1,5 \mathrm{~mm}$ par l'impacteur piézoélectrique. CONCLUSIONS : La formule utilisée dans l'inhalateur produit un microaérosol à gouttelettes suffisamment fines qui imite chaque bouffée de nicotine délivrée au sang artériel par la fumée de tabac. L'absence des produits de combustion comme la chaleur, les carcinogènes et le monoxyde de carbone permet de délivrer la nicotine de façon plus sûre avec l'inhalateur qu'il n'est possible de le faire en fumant.
$\mathrm{W}$ ith the currently available nicotine replacement therapy (gum, patch, nasal inhaler, oral vapour inhaler), most attempts at smoking cessation fail, and relapse rates remain over $75 \%$ (1). A recent review by Pomerleau (2) has given evidence that many, if not most, hard-core smokers suffer from an underlying psychiatric problem that nicotine may help to ameliorate.

None of the available nicotine delivery devices mentioned above mimic a cigarette in terms of the rapid puff-by-puff delivery of an arterial nicotine bolus that reaches the brain within seconds, and this may explain why most individuals relapse to cigarette smoking (3-5). While smoking, an individual's peak arterial plasma nicotine concentration may be 10 times greater than venous concentrations (6). It is only by absorption through the lungs that the rapid arterial bolus nicotine delivery of a cigarette can be achieved, as opposed to the relatively slower venous delivery via buccal or nasal mucosa or skin, which is characteristic of described nicotine delivery devices including the oral vapour inhaler $(3,5)$. The key to efficient arterial (central nervous system) nicotine de- 


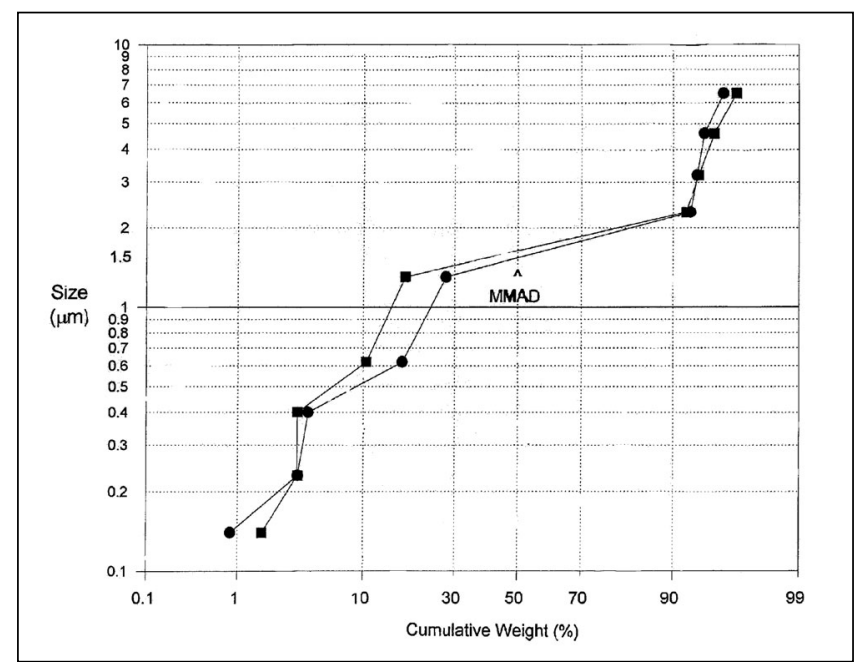

Figure 1) Log-probability plot of hydrofluoroalkane pressurized metered-dose inhaler nicotine in ethanol solution aerosol droplet size distribution as determined by quartz crystal impactor. By this method, the mass median aerodynamic diameter is approximately $1.5 \mu \mathrm{m}$.

livery is in the particle size of the nicotine aerosol. Nicotine vapour entering the mouth condenses onto the mucosal surface of the mouth and throat. Large aerosol droplets affect the upper airway as well. Only nicotine carried by fine droplets and vapour that arises from these fine droplets while they are deep within the lung, is available for absorption into the pulmonary circulation and reaches the brain quickly in high concentration. Cigarette smoke has a mass median aerodynamic diameter (MMAD) of $0.4 \mu \mathrm{m}$ (7). Such small particles deposit mainly in the alveoli of the lung from which they may be rapidly absorbed into the pulmonary circulation.

Pressurized metered-dose inhalers (pMDI) with chlorofluorocarbon (CFC) propellants have been typically solid drug particle (suspension) formulations that deliver about $10 \%$ to $15 \%$ of the nominal dose to the lungs, with the majority being deposited in the upper airway when inhalation of the dose is performed using the closed mouth technique. The MMAD of the aerosol particles associated with such fractional lung delivery is greater than $3 \mu \mathrm{m}$ (8). Although such a relatively larger particle aerosol could reproduce the minute-tominute venous blood nicotine delivery pharmacokinetics of tobacco, the arterial pharmacokinetics that describe nicotine delivery to the brain from tobacco smoke occur on the order of seconds, and would not be approximated by an aerosol greater than $3 \mu \mathrm{m}(3,9,10)$.

CFCs are being phased out due to their atmospheric ozone depleting effects. Consequently, alternative formulations using hydrofluoroalkane (HFA) propellant, which is not ozone depleting, are being produced. For example, beclomethasone has recently been reformulated (3M Pharmaceuticals, $\mathrm{St}$ Paul, Minnesota) as an HFA/ethanol solution formulation that delivers $51 \%$ to $60 \%$ of the deposited dose to the lower respiratory tract. This is due to an unprecedented $1.1 \mu \mathrm{m}$ MMAD of the aerosol droplets, which is made possible by a liquid drug solution, as opposed to a solid drug particle suspension formulation (11).
To mimic the pharmacokinetic properties of a cigarette, not previously possible with existing CFC inhaler formulations and hardware, we sought to test whether an HFA/ethanol/nicotine solution formulation could be used to generate a nicotine aerosol with an MMAD under $2 \mu \mathrm{m}$ for the purpose of displacing tobacco use, either as part of a smoking cessation and/or relapse prevention strategy, or for long term nicotine maintenance.

The long term health consequences of pure nicotine use are not known, but the balance of the available evidence suggests that nicotine is not the primary cause of lung cancer and chronic lung disease caused by tobacco smoke, and that long term nicotine replacement may reduce the enormous disease burden created by smoking (12).

\section{MATERIALS AND METHODS}

Two pMDI canisters were prepared by loading $20 \mathrm{mg}$ nicotine base (Sigma Co, Oakville, Ontario) into each, together with $200 \mathrm{mg}$ ethanol and $10 \mathrm{~g}$ HFA-134a propellant at $-70^{\circ} \mathrm{C}$. This yielded 200 puffs per canister at a nominal unit dose of $100 \mu \mathrm{g} /$ puff, which is approximately that of a single cigarette puff. Canisters, valves and actuators were obtained from 3M Pharmaceuticals.

Sizing was performed at room temperature using the Multi-Stage Liquid Impinger (MSLI) with $20 \mathrm{~mL}$ of $0.2 \mathrm{~N}$ sulfuric acid solvent on each stage. Nicotine concentrations were obtained by ultraviolet (UV) absorbance spectroscopy at $260 \mathrm{~nm}$ (Varian, Cary 50 Probe UV-Visible Spectrophotometer, Mulgrave, Victoria, Australia).

For each sizing experiment, 10 puffs were discharged at $30 \mathrm{~s}$ intervals into a glass throat attached to the impinger with suction air flow set at $60 \mathrm{~L} / \mathrm{min}$. Nicotine that deposited on the liquid stages was shown to be stable, although the nicotine base quickly vapourized from the end-stage filter. In a separate experiment, approximately half of a $100 \mu \mathrm{g}$ dose placed on the end-stage filter was shown to vapourize within $5 \mathrm{~s}$, drawing a lower airflow of $28 \mathrm{~L} / \mathrm{min}$ through the filter.

MSLI sizing data were confirmed using a quartz crystal impactor, the QCM model PC-2 (California Measurements, Sierra Madre, California) at room temperature. Stage droplet size cutoffs for the QCM extend well into the submicron range, and the sampling was at $1 \mathrm{~L} / \mathrm{min}$.

\section{RESULTS}

The solution formulation resulted in a nicotine aerosol particle size distribution with a MMAD of approximately $1.6 \mu \mathrm{m}$ as estimated by the MSLI. Approximately fortyeight per cent of the $100 \mu \mathrm{g}$ nominal dose/puff was lost as vapour from the end-stage filter as the experiment proceeded, because of the volatility of free-base nicotine at room temperature. The majority of this lost fraction may be assumed to have landed initially on the filter as a fine droplet because of the limited saturation of nicotine vapour in air of $2 \mu \mathrm{mol} / \mathrm{L}$ at room temperature (4), which is approximately $10 \%$ of the total nicotine concentration of tobacco 
smoke, and of the aerosol from the present inhaler. This MSLI sizing data and the assumption of ongoing volatile losses from the filter is supported by QCM sizing data where the MMAD was measured at approximately $1.5 \mu \mathrm{m}$ in two separate sizing experiments (Figure 1).

\section{DISCUSSION}

Although the MSLI is unable to provide sizing resolution for droplets under $1.7 \mu \mathrm{m}$ (the particle size cutoff of the last of the four stages), it has the advantage of operating at room temperature, which is the temperature at which the inhaler would most commonly be used. Given the volatility of free-base nicotine in alcohol solution, Anderson Cascade Impactor (Grasby, Smyrna, Georgia) sizing data could only be obtained under conditions of freezing, which would not allow for the observation of any droplet size changes that may occur due to the hygroscopic or colligative properties of nicotine at room temperature. Because our goal was to obtain an approximation of the effective MMAD of our proposed formulation at room temperature, the MSLI's resolution was considered adequate for this purpose.

Although there is no doubt that oropharyngeal droplet deposition occurred with the present inhaler, we were unable to measure it reliably because of the rapid evaporation of nicotine when deposited on the glass throat. In the human airway, such volatility would be expected to skew further the distribution of available nicotine in favour of the lung periphery where air flow rates are lowest; this would leave very little nicotine available to be swallowed, and possibly cause nausea. The vapour component of the aerosol also serves to provide a sensory impact to the upper airway. Upper airway stimulation is thought to be part of the satisfaction of smoking in a manner analogous to the role of chewing and swallowing in eating (13).

A potential concern regarding a high efficiency nicotine delivery device is that it may be possible to overdose with it, but evidence exists to suggest that this could not happen. The dose-response curve for nicotine self-administration in rats is flat in contrast with that seen with cocaine or amphetamines (14). It has been suggested that this results from the adverse effects of nicotine at high doses, such as nausea and vomiting, and that such a flat dose-response curve may explain the relatively narrow range of daily nicotine intake among smokers (15). In fact, the inhalation route of nicotine administration may be the safest in that the effects of a unit dose are felt within seconds, making it impossible to continue inhaling and approach a lethal cumulative dose in the face of severe nausea and vomiting. The therapeutic index of nicotine is higher than most prescription drugs. That is, the lethal dose (approximately $60 \mathrm{mg}$ in an adult) is well beyond the therapeutic dose of 1 to $3 \mathrm{mg}$. It would be just as possible to overdose on cigarettes, by rapid continuous or multiple cigarette smoking, as it would be to overdose on the inhaler. However, acute overdose of nicotine is not known to occur via inhalation of tobacco smoke. It occurs from accidental ingestion of liquid insecticide sprays containing nicotine or from ingestion of tobacco products in children. In other words, nicotine can be ingested in lethal quantities because its effects are delayed by the gastrointestinal route of absorption, contrary to the case with respiratory inhalation. Because the nicotine of the inhaler is contained under pressure, it is not accessible for ingestion. The quantity of ethanol that accompanies the nicotine is trivial. For every cigarette pack equivalent of nicotine consumed ( 20 cigarettes at $1 \mathrm{mg} /$ cigarette), assuming no volatile losses of alcohol, the user would consume $200 \mathrm{mg}$ of alcohol, which is less than $1 \%$ of an ounce $(30 \mathrm{~mL})$.

Another potential concern is the possibility that some users might take up the nicotine habit and become addicted to nicotine via a safer and faster delivery system, whereas the dangers of tobacco might have prevented them from starting in the first place. Even if this phenomenon were to occur, the therapeutic benefits of nicotine delivered by the inhaler is worthy of consideration as a therapeutic option. Because nicotine has effective therapeutic properties as an anxiolytic and antidepressant in individuals with psychiatric co-factors as outlined by Pomerleau (2), the efficient use of nicotine via the inhalation mode of delivery permits the effect to be optimally and quickly titrated by the user on demand, and then it dissipates quickly. Microaerosol inhalation results in a transient exposure of the brain to high levels of nicotine, levels which far exceed those that would be tolerated if administered via a systemic route. Therefore, the inhaler described in the present paper may be an effective vehicle by which to deliver nicotine in the treatment of neurological disorders for which smoking has shown benefit, such as Parkinson's disease, Alzheimer's dementia, Tourette's syndrome, sleep apnea and attention deficit disorders, and for pain relief (16). As well, smoking is clearly inversely related to extrinsic allergic alveolitis, a chronic immunologically mediated lung disease (17). The anti-inflammatory properties of nicotine are thought to be responsible for this therapeutic effect, and are similar to those observed in ulcerative colitis, which is another chronic inflammatory disorder (17). At the very least, such an inhaler system would provide another, perhaps more sensible option, for which an individual could assess the risks and benefits in comparison with smoking.

\section{CONCLUSIONS}

These results are the first evidence of a nicotine aerosol generated from a hand-held device, other than a cigarette, with a sufficiently fine MMAD that potentially deposits a majority of the drug dose in the lungs where it would be available for rapid absorption into the pulmonary circulation.

The inherent simplicity and safety of pMDI technology should allow it to compete successfully with the cigarette in the free market for therapeutic cost effectiveness and/or satisfaction, irrespective of the obvious health risk reduction. This may extend to marijuana cigarettes as well, should they be found to have therapeutic benefits. Combinations of bupropion (Zyban, Glaxo Wellcome, Ulverston, United Kingdom) with the nicotine microaerosol inhaler may be particularly effective at allowing relapse-prone smokers to remain tobacco abstinent over the long term (18). 
ACKNOWLEDGEMENT: This work was supported by a grant from the Ontario Thoracic Society.

\section{REFERENCES}

1. Rodu B. An alternative approach to smoking control. Am J Med Sci 1994;308:32-4.

2. Pomerleau CS. Co-factors for smoking and evolutionary psychobiology. Addiction 1997;92:397-408.

3. Russell MAH. Nicotine replacement: The role of nicotine blood levels, their rate of change, and nicotine tolerance. In: Pomerleau OF, Pomerleau CS, eds. Nicotine Replacement: A Critical Evaluation. New York: Alan R Liss, 1988:63-94.

4. Tonnesen P, Norregaard J, Mikkelsen K, Jorgensen S, Nilsson F. A double-blind trial of a nicotine inhaler for smoking cessation. JAMA 1993;269:1268-71.

5. Bergstrom M, Nordberg A, Lunell E, Antoni G, Langstrom B. Regional deposition of inhaled 11C-nicotine vapour in the human airway as visualized by positron emission tomography. Clin Pharmacol Ther 1995;57:309-17.

6. Henningfield JE. Nicotine medications for smoking cessation. N Engl J Med 1995;333:1196-203.

7. McCusker K, Hiller FC, Wilson JD, McLeod P, Sims R, Bone RC. Dilution of cigarette smoke for real time aerodynamic sizing with a spart analyser. J Aerosol Sci 1982;13:103-10.

8. Dolovich M, Ruffin RE, Roberts R and Newhouse MT. Optimal delivery of aerosols from metered dose inhalers. Chest 1981;80(6 Suppl):911-5.

9. Burch SG, Erbland ML, Gann LP, Hiller FC. Plasma nicotine levels after inhalation of aerosolized nicotine. Am Rev Respir Dis 1989;140:955-7.

10. Herxheimer A, Griffiths, RL, Hamilton B, Wakefield M. Circulatory effects of nicotine aerosol inhalations and cigarette smoking in man. Lancet 1967;2:754-5.

11. Leach C. Enhanced drug delivery through reformulating MDI's with HFA propellants-drug deposition and its effect on preclinical and clinical programs. Respir Drug Delivery 1996;5:133-44.

12. Warner KE, Slade J, Sweanor DT. The emerging market for nicotine maintenance. JAMA 1997;278:1087-92

13. Rose JE. The role of upper airway stimulation in smoking. In: Pomerleau OF, Pomerleau CS, eds. Nicotine Replacement: A Critical Evaluation. New York: Alan R Liss, 1988:95-106.

14. Corrigall WA. Nicotine addiction: considerations in the therapeutic use of nicotine. Med Chem Res 1993;2:603-11.

15. Benowitz NL. Pharmacology of nicotine: addiction and therapeutics. Ann Rev Pharmacol Toxicol 1996;36:597-613.

16. Bannon AW, Decker MW, Holladay MW, et al. Broad-spectrum, non-opioid analgesic activity by selective modulation of neuronal nicotinic acetylcholine receptors. Science 1998;279(5347):77-81.

17. Baron JA. Beneficial effects of nicotine and cigarette smoking: the real, the possible and the spurious. Brit Med Bull 1996;52:58-73.

18. Jorenby DE, Leischow SJ, Nides MA, et al. A controlled trial of sustained-release bupropion, a nicotine patch, or both for smoking cessation. N Engl J Med 1999;340:685-91. 


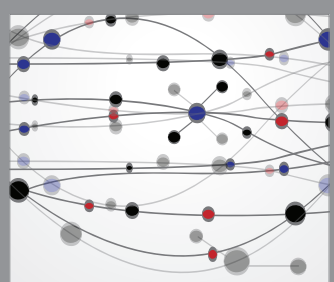

The Scientific World Journal
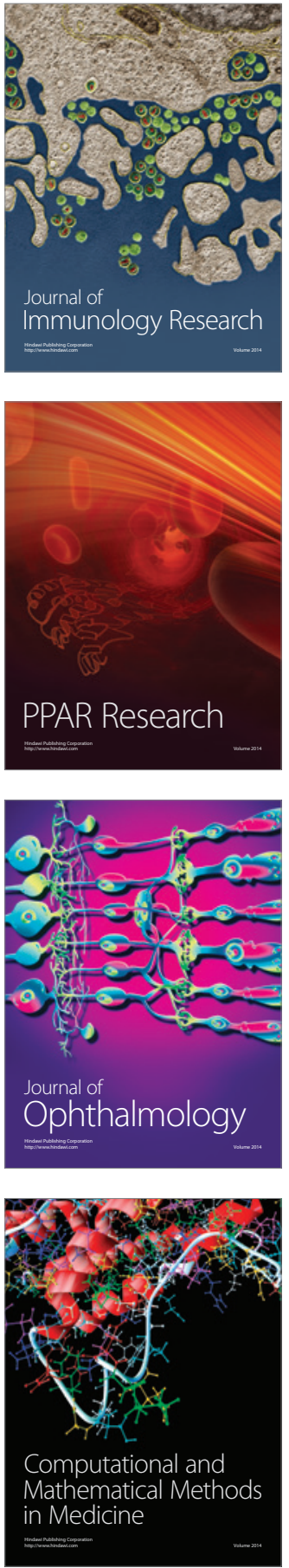

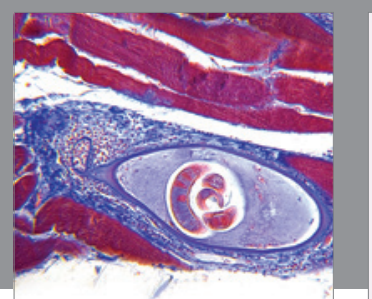

Gastroenterology Research and Practice

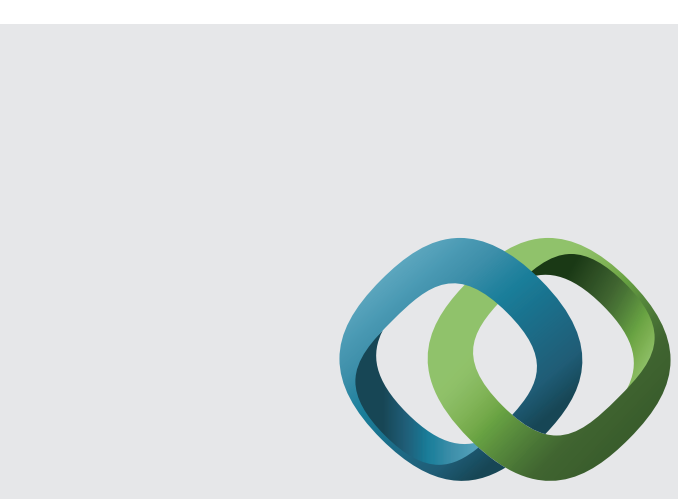

\section{Hindawi}

Submit your manuscripts at

http://www.hindawi.com
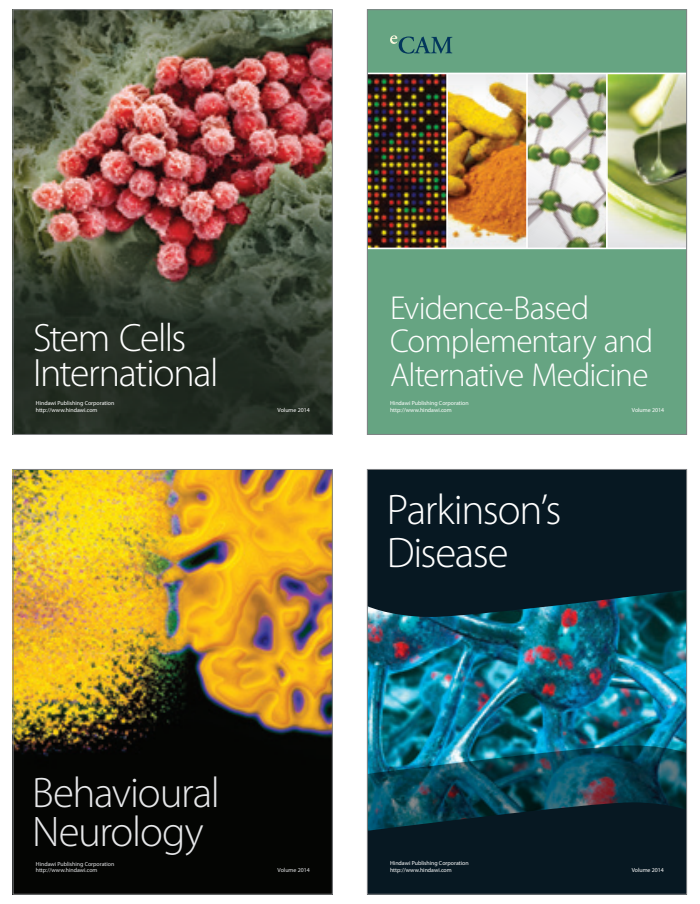
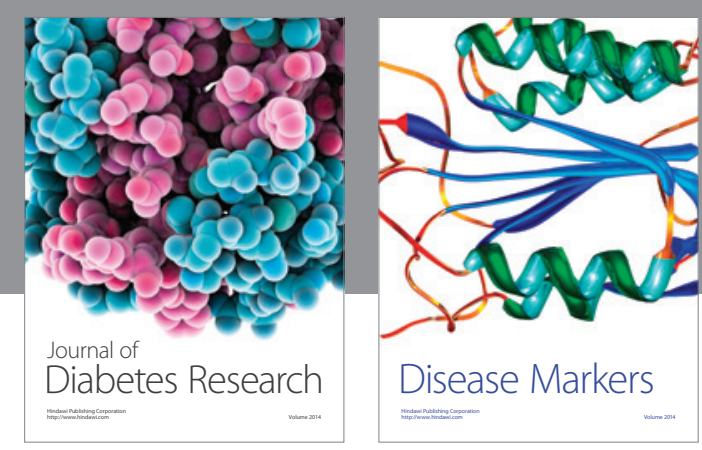

Disease Markers
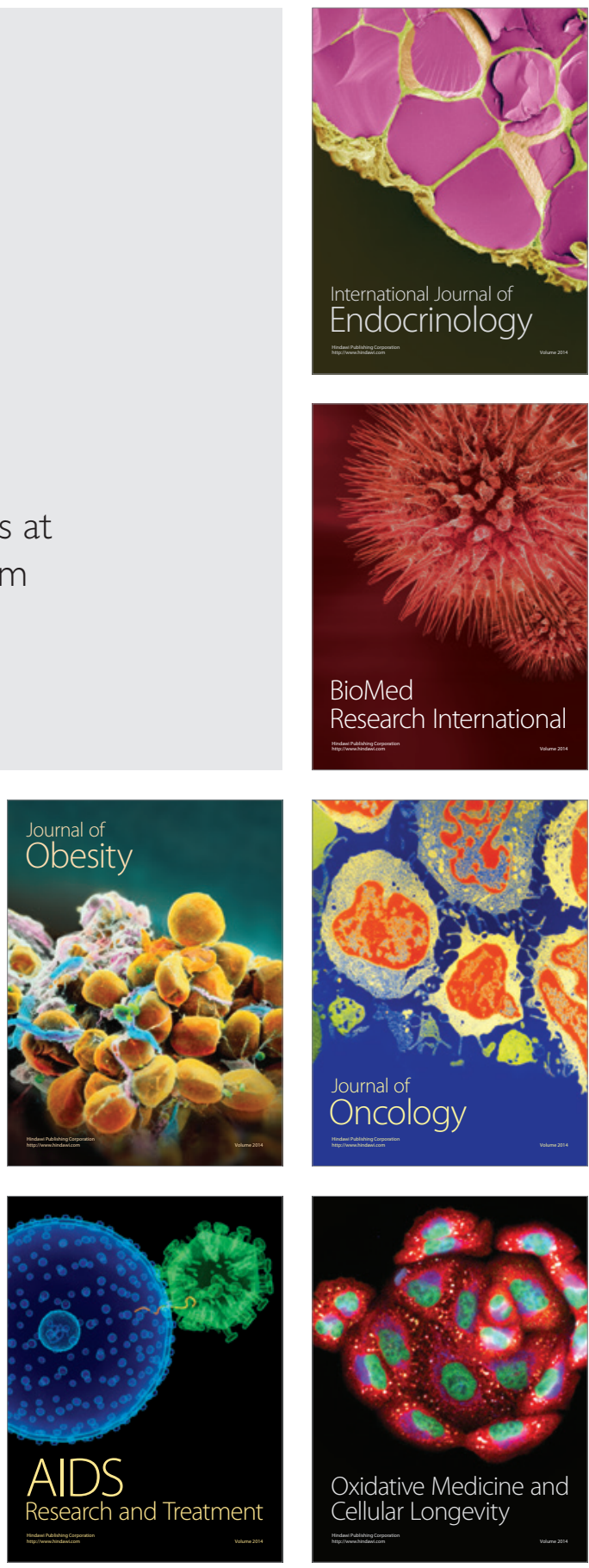